Published in final edited form as:

Curr Opin Nephrol Hypertens. 2019 July ; 28(4): 383-389. doi:10.1097/MNH.0000000000000513.

\title{
Novel Therapeutic Strategies for Renovascular Disease
}

\author{
Alfonso Eirin, MD, Stephen C. Textor, MD, Lilach O. Lerman, MD, PhD \\ Division of Nephrology and Hypertension, Mayo Clinic, Rochester, MN
}

\begin{abstract}
Purpose of review: Renovascular disease (RVD) remains an important cause of hypertension and renal dysfunction. Given the failure of renal revascularization to provide consistent clinical benefit in the Cardiovascular Outcomes for Renal Artery Lesions (CORAL) trial among others, further research has underscored the need for mechanistically targeted interventions to improve renal outcomes in patients in RVD. This review discusses novel therapeutic approaches for RVD in the post-CORAL era.
\end{abstract}

Recent Findings: Emerging evidence indicates that renal inflammation, microvascular remodeling, and mitochondrial damage accelerate progression of renal injury and are important determinants of the response to revascularization. Experimental studies have identified interventions capable of ameliorating renal inflammation (e.g. cytokine inhibitors, mesenchymal stem cells), microvascular remodeling (pro-angiogenic interventions), and mitochondrial injury (mito-protective drugs), alone or combined with renal revascularization, to preserve the structure and function of the post-stenotic kidney. Recent prospective pilot studies in patients with atherosclerotic RVD demonstrate the safety and feasibility of some of such interventions to protect the kidney.

Summary: Experimental studies and pilot clinical trials suggest that therapies targeting renal inflammation, microvascular remodeling, and mitochondrial damage have the potential to preserve the structure and function of the stenotic kidney. Further studies in larger cohorts are needed to confirm their renoprotective effects and clinical role in human RVD.

\section{Keywords}

renovascular disease; hypertension; inflammation; mitochondria; microvasculature

\section{Introduction}

Renovascular disease (RVD) due to atherosclerotic lesions in the renal artery remains an important cause of secondary hypertension and renal failure in the aging population $(1,2)$. Patients with RVD tend to progress to chronic kidney disease and have an increased risk for developing renovascular hypertension (RVH) and cardiovascular complications, increasing morbidity and mortality (3).

Correspondence: Lilach O. Lerman, MD, PhD, Division of Nephrology and Hypertension, Mayo Clinic, 200 First Street SW, Rochester, MN, 55905. Lerman.Lilach@ Mayo.Edu, Phone:(507)-266-9376, Fax:(507)-266-9316.

Conflict of Interest

None 
While restoring renal artery patency by revascularization would seem to be a logical approach to preserve the renal parenchyma beyond a stenotic lesion, results from clinical trials fail to demonstrate consistent recovery of post-stenotic kidney function. Two randomized clinical trials, the Angioplasty and Stenting for Renal Artery Lesions (ASTRAL) (4) and Stent Placement and Blood Pressure and Lipid-Lowering for the Prevention of Progression of Renal Dysfunction Caused by Atherosclerotic Ostial Stenosis of the Renal Artery (STAR) trials (5) concluded that compared with medical therapy, revascularization carries some substantial risk, without adding benefit with respect to renal function.

Cooper and colleagues published the results of the Cardiovascular Outcomes for Renal Artery Lesions (CORAL) trial in 2014 (6). In this multi-center, randomized, controlled trial, patients with atherosclerotic RVD were randomly assigned to medical therapy plus percutaneous transluminal renal angioplasty (PTRA) or medical therapy alone. After a median follow-up of 43 months, renal revascularization failed to confer incremental benefit over conventional medical therapy with respect to prevention of clinical cardiovascular events and renal dysfunction. Taken together with the conclusions of a Medicare and Medicaid review panel (7), such outcome results reduced selection of patients for renal revascularization. The number of PTRA/stenting procedures for atherosclerotic RVD has fallen in recent years (8). It has become clear that restoring blood flow to the chronically ischemic kidney does not by itself predictably restore renal function. Renal revascularization procedures are currently reserved for patients with severe and progressive RVD.

An important corollary to these observations has been to emphasize the importance of research efforts directed to better define the main determinants of the response to renal revascularization and to develop novel interventions to improve renal outcomes (9). A major paradigm shift in RVD is the understanding that the natural history of the disease involves transition from a hemodynamic component to a pro-inflammatory and pro-fibrotic disease (10). While early RVD is characterized by reduction in renal blood flow (RBF), activation of inflammatory and pro-fibrotic pathways can subsequently produce significant renal damage not directly related to the degree or hemodynamic impact of stenosis. Therefore, extensive parenchymal injury, including inflammation, fibrosis, and microvascular remodeling, imparts irreversible injury in the post-stenotic kidney.

Several studies in recent years have tested the efficacy of interventions to attenuate renal inflammation and preserve microvascular integrity or renal mitochondrial structure and function in RVD. This mini-review briefly discusses these therapeutic approaches for RVD in the post-CORAL era. None have yet been approved for routine clinical use. Studies in both animal models and human subjects have been summarized in order to highlight the potential of these interventions to ameliorate parenchymal injury and foster tissue repair in RVD.

\section{Anti-inflammatory interventions}

Several lines of evidence have shown that inflammation markedly aggravates renal dysfunction in experimental RVD. We have shown in post-stenotic swine kidneys increased 
expression of pro-inflammatory cytokines, such as chemokine monocyte chemoattractant protein (MCP)-1 (11) and tumor necrosis factor-a (12), associated with inflammatory cell infiltration and renal dysfunction (13). Data from renal biopsies and nephrectomy specimens from patients with RVD, characterized by macrophage infiltration and fibrosis (14), support these observations. Furthermore, renal vein blood from post-stenotic swine (15) and human (16) kidneys contains multiple active inflammatory biomarkers associated with episodes of acute kidney injury and reduced function (17). Importantly, release of pro-inflammatory cytokines inversely correlates with renal functional recovery after PTRA (15), underscoring the dominant role of inflammation in determining response to renal revascularization in RVD.

In light of these observations, therapies targeting inflammation-related pathways have emerged as novel interventions to preserve the structure and function of the post-stenotic kidney (11). MCP-1 inhibition in swine RVD improves post-stenotic RBF, glomerular filtration rate (GFR), and endothelial function (11), and attenuates left ventricular hypertrophy and diastolic dysfunction (18). Therefore, blunting renal inflammation could potentially introduce a therapeutic target in RVD and hypertensive cardiomyopathy.

Likewise, mesenchymal stem cells (MSCs), which possess important immunomodulatory and ant-inflammatory properties, ameliorate post-stenotic injury and recover function in swine and murine models of RVD $(19,20)$. Renal subcapsular delivery of autologous MSCs improves renal morphology and reduces fibrosis in a 2-Kidneys 1-Clip model (21). Similarly, intra-arterial delivery of adipose tissue-derived MSCs ameliorates post-stenotic injury in swine RVD $(22,23)$. These beneficial effects are partly mediated by modulation of inflammatory pathways, including inducing a macrophage phenotype shift from inflammatory (M1) to reparative (M2) populations (24).

Additionally, intra-arterial MSC delivery during PTRA restores stenotic-kidney function, reduces inflammation (25), and improves medullary oxygenation (26) after revascularization in swine, supporting the reno-protective properties of this anti-inflammatory intervention. The observation that MSC delivery with and without PTRA also decreases myocardial remodeling and improves cardiac function in swine $\operatorname{RVD}(27,28)$ suggests a therapeutic potential for MSCs in blunting systemic complications of chronic experimental RVH.

Importantly, many of these findings were recently confirmed in a pilot clinical trial. Intraarterial infusion of autologous adipose tissue-derived MSCs was safe and well tolerated in patients with atherosclerotic RVD without revascularization, and associated with increased cortical perfusion and RBF 3 months later (29). Furthermore, renal vein levels of proinflammatory cytokines tended to decrease after MSC therapy, underscoring the potential of anti-inflammatory cell therapy to preserve the post-stenotic human kidney (30).

MSCs achieve repair by paracrine mechanisms, including release of growth factors and extracellular-vesicles (EVs) $(31,32)$. MSC-derived EVs carry several anti-inflammatory genes (33) and proteins $(34,35)$. Intra-renal delivery of EV's decreases renal inflammation and injury in experimental RVD $(36,37)$. However, these beneficial effects are abolished in EVs depleted of interleukin-10, supporting its contribution to EV function (37). Taken 
together, these observations suggest that anti-inflammatory interventions can ameliorate injury and preserve function in the post-ischemic kidney. Additional experimental and clinical trials with longer follow-up periods are warranted to confirm their safety and longterm clinical efficacy in RVD.

\section{Therapies to restore the renal microcirculation}

Microvascular remodeling and rarefaction are important determinants of renal dysfunction in RVD, and may compromise renal outcomes after revascularization. Inflammation, oxidative stress, and fibrosis all damage the structure and function of the renal microvasculature, potentiating renal damage (38). Tortuous and leaky vessels in turn permit extravasation of inflammatory mediators and infiltration of inflammatory cells into the interstitium.

Microvascular remodeling and loss also impair renal perfusion and amplify tissue hypoxia, aggravating renal parenchymal injury and impairing functional recovery after PTRA. Indeed, the number of small outer cortical microvessels correlates directly with GFR in swine RVD (39). Remodeling of intra-renal vessels also correlates with progressive deterioration of perfusion, RBF, and tubular function (40, 41).

RVD-induced changes in the renal microvasculature are frequently associated with decreased expression of angiogenic factors, including vascular endothelial (VEGF) and hepatocyte (HGF) growth factors (42). These factors participate in microvascular protection, repair, and proliferation, and deficiency in their renal expression likely reflects "defective angiogenesis" that aggravates stenotic kidney microvascular damage (42). Targeted interventions that preserve or promote proliferation of the renal microvasculature have been postulated to attenuate injury and improve renal function in RVD.

Indeed, intra-renal delivery of VEGF increases angiogenic signaling and preserves the microvasculature in swine RVD (40). Furthermore, its delivery combined with PTRA improves microvascular density and renal function (43), consistent with the premise that microvascular disease determines responses to revascularization in experimental RVD. Similarly, intra-renal HGF improves RBF and GFR in the swine stenotic kidney (44). However, high concentrations of these compounds in the kidney are often needed, increasing the likelihood of side effects (45). In addition, RVD-induced changes in glomerular filtration and tubular function may compromise the distribution of these drugs to the kidney.

Selective targeting of the kidney may increase the efficacy of pro-angiogenic factors and minimize extra-renal side effects. In swine RVD, systemic biopolymer-stabilized, elastinlike polypeptide (ELP)-delivered VEGF promotes therapeutic angiogenesis in the poststenotic kidney $(46,47)$. Furthermore, longer plasma half-life and higher renal selectivity can be achieved by modifying ELP with a seven-amino-acid, kidney-targeting peptide (KTP) and a cysteine residue (48). Therefore, kidney-specific delivery methods can minimize extrarenal side effects and enhance drug efficacy, providing functional recovery in RVD.

Regenerative therapy with endothelial progenitor cells (EPCs) and MSCs may also preserve and/or repair the microvasculature in animal models of renal disease. These cells express and secrete VEGF and may incorporate into vascular structures $(27,49)$, so that intra-renal 
delivery of EPCs $(22,49-52)$ or MSCs $(24,25)$ restores the post-stenotic kidney microcirculation and function in experimental RVD. Furthermore, these cells can blunt pathways that contribute to microvascular damage, including oxidative stress, apoptosis, inflammation, and development of fibrosis. Development of techniques to deliver reparative cells to the kidney cells using targeting or "homing" signals may allow systemic (intravenous) administration and expedite clinical translation of this approach (53).

Recent studies in swine RVD have shown that six sessions of low-energy external ultrasonic shockwave (SW) increase microvascular density and alleviate renal dysfunction distal to a stenosis $(54,55)$. This mechanical stimulus upregulates renal expression of pro-angiogenic pathways $(56,57)$, improving the ischemic kidney microcirculation. Importantly, this novel therapy does not cause detectable kidney injury in normal pigs, underscoring its safety (54). A recent pilot study in patients with diabetic nephropathy reported safety of SW therapy in human kidneys as well (58). Further studies are needed to define the optimal regimen of SW treatment in the ischemic kidney.

\section{Mitoprotective drugs}

A growing body of evidence implicates renal mitochondrial dysfunction in the pathogenesis of tissue damage associated with RVD (59). One of the mechanisms involved may include activation of angiotensin-II type-2 receptors in the inner mitochondrial membrane (60), which stimulate production of mitochondrial reactive oxygen species (ROS) $(61,62)$ and induce apoptosis of renal tubular cells (63). Angiotensin-II also increases cytosolic ROS, favoring oxidation of mitochondrial lipids and proteins (64), and mitochondrial-DNA mutations (65). This may in turn prevent transcription of mitochondrial proteins implicated in ATP synthesis and respiration (66). ROS can also trigger the formation of the mitochondrial permeability transition pore, and release of cytochrome-c and mitochondrial ROS to the cytosol $(67,68)$, contributing to apoptosis and cellular oxidative stress (69). Extracellular matrix accumulation can directly damage mitochondria and promote apoptosis (70). Hence, mitochondrial damage and dysfunction compromise overall cell functioning, instigating a progressive cycle of mitochondrial injury and cellular damage in RVD.

The mitoprotective drug elamipretide (ELAM) prevents oxidation of the mitochondrial inner membrane phospholipid cardiolipin and formation of the mitochondrial permeability transition pore, and exerts important reno-protective effects in several models of kidney injury. We have shown that ELAM attenuates stenotic-kidney microvascular loss and injury, and improves oxygenation, hemodynamics, and function in pigs with RVD (71). Furthermore, adjunctive ELAM during renal reperfusion attenuates microvascular rarefaction (Figure 1) and structural damage, and improves renal function 4 weeks later (12). ELAM also attenuated left ventricular remodeling and preserved diastolic function in swine RVD $(72,73)$, underscoring its capability to ameliorate RVH-induced cardiomyopathy.

Notably, delivery of ELAM before and during renal artery stenting in human RVD attenuated post-procedural hypoxia, increased RBF, and improved GFR (74). Infused systemically, this adjunctive intervention is noninvasive and clinical feasible. Therefore, 
targeted mitochondrial protection might minimize procedure-associated ischemic injury and improve outcomes after PTRA.

\section{Other reno-protective strategies}

Additional noteworthy interventions include antioxidants, endothelin-1 blockers, angiotensin-II inhibitors, and statins. Increased oxidative stress in the stenotic kidney is blunted by antioxidant vitamins (75), which decrease inflammation and fibrosis, and restore microvascular architecture (76). Alas, they paradoxically increase oxidative stress in healthy pigs (77), which may limit their widespread use. Endothelin-A receptor blockade preserves function and microvasculature in the stenotic kidney (78), and enhances functional recovery after PTRA in swine RVD (79).

Agents that block the renin-angiotensin system (RAAS) and cholesterol lowering therapy with statins define optimal management of patients with RVD. Both angiotensin-convertingenzyme inhibitors (ACEi) and angiotensin-receptor-blockers (ARBs) have been associated with long-term mortality benefits compared to other antihypertensive drugs $(80,81)$. The CORAL study found that ACEi and ARBs were well-tolerated, and patients treated with these drugs before enrollment were likely to achieve blood pressure goals at the end of the study (82). Although these drugs reduce filtration pressures and may acutely decrease poststenotic kidney GFR, their beneficial tissue effects are superior to triple-therapy. Indeed, treatment with valsartan for 4 weeks not only decreased blood pressure, but also stimulated microvascular density and improved tubular function in swine RVD (83).

Statins are also known for pleiotropic effects, and may slow progression of post-stenotic kidney injury in human RVD by decreasing oxidative stress, endothelial dysfunction, and tissue fibrosis (84). We have also shown in swine RVD that chronic simvastatin supplementation ameliorates stenotic-kidney microvascular remodeling (85), and prevents apoptosis of endothelial progenitor cells, underscoring their potential to preserve renal repair mechanisms (86), independent of lipid-lowering. Therefore, these observations support the early use of RAAS blockers and statins in patients with RVD. Lastly, dampening pro-fibrotic pathways like transforming growth factor- $\beta / S \operatorname{mad} 3$ signaling may also decrease kidney scarring (87), and thereby protect the kidney in RVD.

\section{Conclusions and perspectives}

For many years, management of patients with RVD was based primarily on the assumption that restoring renal artery patency would improve renal function. However, disappointing results from several clinical trials have undermined this assumption and led to a dramatic reduction in clinical revascularization. Notwithstanding, these observations have magnified the importance of research to define the mechanisms of irreversible renal injury and develop novel therapies to improve renal outcomes in these patients. Anti-inflammatory, proangiogenic, and mitoprotective interventions have emerged as powerful strategies and showed promising results in experimental RVD, particularly in conjunction with renal revascularization. 
Importantly, the safety and potential efficacy of several of these novel interventions have been validated in pilot clinical trials in patients with atherosclerotic RVD. Notably, the effects of these strategies to protect and/or restore renal function may be independent of reversing the effect of RVD on blood pressure regulation. Ultimately, their roles likely will be adjunctive when combined with selective restoration of blood flow to the affected kidneys. Further studies are warranted to establish their clinical role as a multipronged approach for preservation and recovery of renal function in human clinical RVD.

\section{Acknowledgements}

Financial support and sponsorship

Partly supported by the NIH (DK100081, DK106427, DK104273, DK120292, HL123160 and DK102325).

\section{REFERENCES AND RECOMMENDED READING}

Papers of particular interest, published within the annual period of review, have been highlighted as:

* of special interest

** of outstanding interest

1. Hansen KJ, Edwards MS, Craven TE, Cherr GS, Jackson SA, Appel RG, et al. Prevalence of renovascular disease in the elderly: a population-based study. J Vasc Surg 2002;36(3):443-51. [PubMed: 12218965]

2. Coen G, Manni M, Giannoni MF, Bianchini G, Calabria S, Mantella D, et al. Ischemic nephropathy in an elderly nephrologic and hypertensive population. Am J Nephrol 1998;18(3):221-7. [PubMed: 9627038]

3. US Renal Data System 2016 Annual Data Report: Epidemiology of Kidney Disease in the United States. Am J Kidney Dis 2017;69(3S1):A4.

4. Investigators A, Wheatley K, Ives N, Gray R, Kalra PA, Moss JG, et al. Revascularization versus medical therapy for renal-artery stenosis. N Engl J Med 2009;361(20):1953-62. [PubMed: 19907042]

5. Bax L, Woittiez AJ, Kouwenberg HJ, Mali WP, Buskens E, Beek FJ, et al. Stent placement in patients with atherosclerotic renal artery stenosis and impaired renal function: a randomized trial. Ann Intern Med 2009;150(12):840-8, W150-1. [PubMed: 19414832]

6. Cooper CJ, Murphy TP, Cutlip DE, Jamerson K, Henrich W, Reid DM, et al. Stenting and medical therapy for atherosclerotic renal-artery stenosis. N Engl J Med 2014;370(1):13-22. [PubMed: 24245566]

7. Balk E, Raman G, Chung M, Ip S, Tatsioni A, Alonso A, et al. Effectiveness of management strategies for renal artery stenosis: a systematic review. Ann Intern Med 2006;145(12):901-12. [PubMed: 17062633]

8. Liang P, Hurks R, Bensley RP, Hamdan A, Wyers M, Chaikof E, et al. The rise and fall of renal artery angioplasty and stenting in the United States, 1988-2009. J Vasc Surg 2013;58(5):1331-8 e1. [PubMed: 23810297]

9. Textor SC, Misra S, Oderich GS. Percutaneous revascularization for ischemic nephropathy: the past, present, and future. Kidney Int 2013;83(1):28-40. [PubMed: 23151953]

10. Eirin A, Textor SC, Lerman LO. Emerging Paradigms in Chronic Kidney Ischemia. Hypertension 2018;72(5):1023-30. [PubMed: 30354824]

11. Zhu XY, Chade AR, Krier JD, Daghini E, Lavi R, Guglielmotti A, et al. The chemokine monocyte chemoattractant protein-1 contributes to renal dysfunction in swine renovascular hypertension. J Hypertens 2009;27(10):2063-73. [PubMed: 19730125] 
12. Eirin A, Li Z, Zhang X, Krier JD, Woollard JR, Zhu XY, et al. A mitochondrial permeability transition pore inhibitor improves renal outcomes after revascularization in experimental atherosclerotic renal artery stenosis. Hypertension 2012;60(5):1242-9. [PubMed: 23045468]

13. Chade AR, Rodriguez-Porcel M, Herrmann J, Zhu X, Grande JP, Napoli C, et al. Antioxidant intervention blunts renal injury in experimental renovascular disease. J Am Soc Nephrol 2004;15(4):958-66. [PubMed: 15034098]

14. Gloviczki ML, Keddis MT, Garovic VD, Friedman H, Herrmann S, McKusick MA, et al. TGF expression and macrophage accumulation in atherosclerotic renal artery stenosis. Clin J Am Soc Nephrol 2013;8(4):546-53. [PubMed: 23258796]

15. Eirin A, Ebrahimi B, Zhang X, Zhu XY, Tang H, Crane JA, et al. Changes in glomerular filtration rate after renal revascularization correlate with microvascular hemodynamics and inflammation in Swine renal artery stenosis. Circ Cardiovasc Interv 2012;5(5):720-8. [PubMed: 23048054]

16. Eirin A, Gloviczki ML, Tang H, Gossl M, Jordan KL, Woollard JR, et al. Inflammatory and injury signals released from the post-stenotic human kidney. Eur Heart J 2013;34(7):540-8a. [PubMed: 22771675]

17. Eirin A, Gloviczki ML, Tang H, Rule AD, Woollard JR, Lerman A, et al. Chronic renovascular hypertension is associated with elevated levels of neutrophil gelatinase-associated lipocalin. Nephrol Dial Transplant 2012;27(11):4153-61. [PubMed: 22923545]

18. Lin J, Zhu X, Chade AR, Jordan KL, Lavi R, Daghini E, et al. Monocyte chemoattractant proteins mediate myocardial microvascular dysfunction in swine renovascular hypertension. Arterioscler Thromb Vasc Biol 2009;29(11):1810-6. [PubMed: 19628782]

19. Eirin A, Lerman LO. Mesenchymal stem cell treatment for chronic renal failure. Stem Cell Res Ther 2014;5(4):83. [PubMed: 25158205]

20. Oliveira-Sales EB, Boim MA. Mesenchymal stem cells and chronic renal artery stenosis. Am J Physiol Renal Physiol 2016;310(1):F6-9. [PubMed: 26538439]

21. Lira R, Oliveira M, Martins M, Silva C, Carvalho S, Stumbo AC, et al. Transplantation of bone marrow-derived MSCs improves renal function and $\mathrm{Na}(+)+\mathrm{K}(+)$-ATPase activity in rats with renovascular hypertension. Cell Tissue Res 2017;369(2):287-301. [PubMed: 28374150]

22. Zhu XY, Urbieta-Caceres V, Krier JD, Textor SC, Lerman A, Lerman LO. Mesenchymal stem cells and endothelial progenitor cells decrease renal injury in experimental swine renal artery stenosis through different mechanisms. Stem Cells 2013;31(1):117-25. [PubMed: 23097349]

23. Zhu XY, Ebrahimi B, Eirin A, Woollard JR, Tang H, Jordan KL, et al. Renal Vein Levels of MicroRNA-26a Are Lower in the Poststenotic Kidney. J Am Soc Nephrol 2015;26(6):1378-88. [PubMed: 25270070]

24. Eirin A, Zhang X, Zhu XY, Tang H, Jordan KL, Grande JP, et al. Renal vein cytokine release as an index of renal parenchymal inflammation in chronic experimental renal artery stenosis. Nephrol Dial Transplant 2014;29(2):274-82. [PubMed: 24097799]

25. Eirin A, Zhu XY, Krier JD, Tang H, Jordan KL, Grande JP, et al. Adipose tissue-derived mesenchymal stem cells improve revascularization outcomes to restore renal function in swine atherosclerotic renal artery stenosis. Stem Cells 2012;30(5):1030-41. [PubMed: 22290832]

26. Ebrahimi B, Eirin A, Li Z, Zhu XY, Zhang X, Lerman A, et al. Mesenchymal stem cells improve medullary inflammation and fibrosis after revascularization of swine atherosclerotic renal artery stenosis. PLoS One 2013;8(7):e67474. [PubMed: 23844014]

27. Eirin A, Zhu XY, Ferguson CM, Riester SM, van Wijnen AJ, Lerman A, et al. Intra-renal delivery of mesenchymal stem cells attenuates myocardial injury after reversal of hypertension in porcine renovascular disease. Stem Cell Res Ther 2015;6:7. [PubMed: 25599803]

28. Eirin A, Zhu XY, Ebrahimi B, Krier JD, Riester SM, van Wijnen AJ, et al. Intrarenal Delivery of Mesenchymal Stem Cells and Endothelial Progenitor Cells Attenuates Hypertensive Cardiomyopathy in Experimental Renovascular Hypertension. Cell Transplant 2015;24(10):204153. [PubMed: 25420012]

** 29. Saad A, Dietz AB, Herrmann SMS, Hickson LJ, Glockner JF, McKusick MA, et al. Autologous Mesenchymal Stem Cells Increase Cortical Perfusion in Renovascular Disease. J Am Soc Nephrol 2017;28(9):2777-85. [PubMed: 28461553] The first study testing the safety and efficacy of mesenchymal stem cells in patients with renovascular disease. 
30. Saad A, Herrmann SM, Textor SC. Chronic renal ischemia in humans: can cell therapy repair the kidney in occlusive renovascular disease? Physiology (Bethesda) 2015;30(3):175-82. [PubMed: 25933818]

31. Aghajani Nargesi A, Lerman LO, Eirin A. Mesenchymal stem cell-derived extracellular vesicles for kidney repair: current status and looming challenges. Stem Cell Res Ther 2017;8(1):273. [PubMed: 29202871]

32. Nargesi AA, Lerman LO, Eirin A. Mesenchymal Stem Cell-derived Extracellular Vesicles for Renal Repair. Curr Gene Ther 2017;17(1):29-42. [PubMed: 28403795]

33. Eirin A, Riester SM, Zhu XY, Tang H, Evans JM, O’Brien D, et al. MicroRNA and mRNA cargo of extracellular vesicles from porcine adipose tissue-derived mesenchymal stem cells. Gene 2014;551(1):55-64. [PubMed: 25158130]

34. Eirin A, Zhu XY, Puranik AS, Woollard JR, Tang H, Dasari S, et al. Comparative proteomic analysis of extracellular vesicles isolated from porcine adipose tissue-derived mesenchymal stem/ stromal cells. Sci Rep 2016;6:36120. [PubMed: 27786293]

35. Eirin A, Zhu XY, Puranik AS, Woollard JR, Tang H, Dasari S, et al. Integrated transcriptomic and proteomic analysis of the molecular cargo of extracellular vesicles derived from porcine adipose tissue-derived mesenchymal stem cells. PLoS One 2017;12(3):e0174303. [PubMed: 28333993]

36. Eirin A, Zhu XY, Jonnada S, Lerman A, van Wijnen AJ, Lerman LO. Mesenchymal Stem CellDerived Extracellular Vesicles Improve the Renal Microvasculature in Metabolic Renovascular Disease in Swine. Cell Transplant 2018;27(7):1080-95. [PubMed: 29954220]

* 37. Eirin A, Zhu XY, Puranik AS, Tang H, McGurren KA, van Wijnen AJ, et al. Mesenchymal stem cell-derived extracellular vesicles attenuate kidney inflammation. Kidney Int 2017;92(1):114-24. [PubMed: 28242034] Demonstrates that intrarenal stem cell-derived extracellular vesicles improve renal structure and function in experimental renovascular disease.

38. Eirin A, Lerman LO. Darkness at the end of the tunnel: poststenotic kidney injury. Physiology (Bethesda) 2013;28(4):245-53. [PubMed: 23817799]

39. Eirin A, Zhu XY, Urbieta-Caceres VH, Grande JP, Lerman A, Textor SC, et al. Persistent kidney dysfunction in swine renal artery stenosis correlates with outer cortical microvascular remodeling. Am J Physiol Renal Physiol 2011;300(6):F1394-401. [PubMed: 21367913]

40. Chade AR, Kelsen S. Reversal of renal dysfunction by targeted administration of VEGF into the stenotic kidney: a novel potential therapeutic approach. Am J Physiol Renal Physiol 2012;302(10):F1342-50. [PubMed: 22357917]

41. Iliescu R, Fernandez SR, Kelsen S, Maric C, Chade AR. Role of renal microcirculation in experimental renovascular disease. Nephrol Dial Transplant 2010;25(4):1079-87. [PubMed: 19934087]

42. Chade AR. Renal vascular structure and rarefaction. Compr Physiol 2013;3(2):817-31. [PubMed: 23720331]

43. Chade AR, Kelsen S. Renal microvascular disease determines the responses to revascularization in experimental renovascular disease. Circ Cardiovasc Interv 2010;3(4):376-83. [PubMed: 20587789]

44. Stewart N, Chade AR. Renoprotective effects of hepatocyte growth factor in the stenotic kidney. Am J Physiol Renal Physiol 2013;304(6):F625-33. [PubMed: 23269649]

45. Bartoli E Adverse effects of drugs on the kidney. Eur J Intern Med 2016;28:1-8. [PubMed: 26725327]

46. Chade AR, Tullos NA, Harvey TW, Mahdi F, Bidwell GL 3rd. Renal Therapeutic Angiogenesis Using a Bioengineered Polymer-Stabilized Vascular Endothelial Growth Factor Construct. J Am Soc Nephrol 2016;27(6):1741-52. [PubMed: 26541349]

47. Chade AR, Williams ML, Guise E, Vincent LJ, Harvey TW, Kuna M, et al. Systemic biopolymerdelivered vascular endothelial growth factor promotes therapeutic angiogenesis in experimental renovascular disease. Kidney Int 2018;93(4):842-54. [PubMed: 29273331]

48. Bidwell GL 3rd, Mahdi F, Shao Q, Logue OC, Waller JP, Reese C, et al. A kidney-selective biopolymer for targeted drug delivery. Am J Physiol Renal Physiol 2017;312(1):F54-F64. [PubMed: 27784692] 
49. Chade AR, Zhu X, Lavi R, Krier JD, Pislaru S, Simari RD, et al. Endothelial progenitor cells restore renal function in chronic experimental renovascular disease. Circulation 2009;119(4):54757. [PubMed: 19153272]

50. Eirin A, Zhu XY, Li Z, Ebrahimi B, Zhang X, Tang H, et al. Endothelial outgrowth cells shift macrophage phenotype and improve kidney viability in swine renal artery stenosis. Arterioscler Thromb Vasc Biol 2013;33(5):1006-13. [PubMed: 23430615]

51. Ebrahimi B, Li Z, Eirin A, Zhu XY, Textor SC, Lerman LO. Addition of endothelial progenitor cells to renal revascularization restores medullary tubular oxygen consumption in swine renal artery stenosis. Am J Physiol Renal Physiol 2012;302(11):F1478-85. [PubMed: 22419692]

52. Chade AR, Zhu XY, Krier JD, Jordan KL, Textor SC, Grande JP, et al. Endothelial progenitor cells homing and renal repair in experimental renovascular disease. Stem Cells 2010;28(6):1039-47. [PubMed: 20506499]

53. Zou X, Jiang K, Puranik AS, Jordan KL, Tang H, Zhu X, et al. Targeting Murine Mesenchymal Stem Cells to Kidney Injury Molecule-1 Improves Their Therapeutic Efficacy in Chronic Ischemic Kidney Injury. Stem Cells Transl Med 2018;7(5):394-403. [PubMed: 29446551]

54. Zhang X, Krier JD, Amador Carrascal C, Greenleaf JF, Ebrahimi B, Hedayat AF, et al. LowEnergy Shockwave Therapy Improves Ischemic Kidney Microcirculation. J Am Soc Nephrol 2016;27(12):3715-24. [PubMed: 27297945]

55. Zhang X, Zhu X, Ferguson CM, Jiang K, Burningham T, Lerman A, et al. Magnetic resonance elastography can monitor changes in medullary stiffness in response to treatment in the swine ischemic kidney. MAGMA 2018;31(3):375-82. [PubMed: 29289980]

56. Luu NT, Glen KE, Egginton S, Rainger GE, Nash GB. Integrin-substrate interactions underlying shear-induced inhibition of the inflammatory response of endothelial cells. Thromb Haemost 2013;109(2):298-308. [PubMed: 23238518]

57. Zebda N, Dubrovskyi O, Birukov KG. Focal adhesion kinase regulation of mechanotransduction and its impact on endothelial cell functions. Microvasc Res 2012;83(1):71-81. [PubMed: 21741394]

58. Skov-Jeppesen SM, Yderstraede KB, Bistrup C, Jensen BL, Marcussen N, Hanna M, et al. Lowintensity shockwave therapy in the treatment of diabetic nephropathy: a prospective Phase 1 study. Nephrol Dial Transplant 2018.

59. Eirin A, Lerman A, Lerman LO. Mitochondria: a pathogenic paradigm in hypertensive renal disease. Hypertension 2015;65(2):264-70. [PubMed: 25403611]

60. Abadir PM, Foster DB, Crow M, Cooke CA, Rucker JJ, Jain A, et al. Identification and characterization of a functional mitochondrial angiotensin system. Proc Natl Acad Sci U S A 2011;108(36):14849-54. [PubMed: 21852574]

61. Griendling KK, Minieri CA, Ollerenshaw JD, Alexander RW. Angiotensin II stimulates NADH and NADPH oxidase activity in cultured vascular smooth muscle cells. Circulation research 1994;74(6):1141-8. [PubMed: 8187280]

62. Dikalov SI, Nazarewicz RR, Bikineyeva A, Hilenski L, Lassegue B, Griendling KK, et al. Nox2induced production of mitochondrial superoxide in angiotensin II-mediated endothelial oxidative stress and hypertension. Antioxid Redox Signal 2014;20(2):281-94. [PubMed: 24053613]

63. Bhaskaran M, Reddy K, Radhakrishanan N, Franki N, Ding G, Singhal PC. Angiotensin II induces apoptosis in renal proximal tubular cells. American journal of physiology Renal physiology 2003;284(5):F955-65. [PubMed: 12527553]

64. Andrukhiv A, Costa AD, West IC, Garlid KD. Opening mitoKATP increases superoxide generation from complex I of the electron transport chain. American journal of physiology Heart and circulatory physiology 2006;291(5):H2067-74. [PubMed: 16798828]

65. Navarro A Mitochondrial enzyme activities as biochemical markers of aging. Mol Aspects Med 2004;25(1-2):37-48. [PubMed: 15051315]

66. Paradies G, Petrosillo G, Pistolese M, Ruggiero FM. Reactive oxygen species affect mitochondrial electron transport complex I activity through oxidative cardiolipin damage. Gene 2002;286(1): 135-41. [PubMed: 11943469]

67. Szeto HH. First-in-class cardiolipin-protective compound as a therapeutic agent to restore mitochondrial bioenergetics. Br J Pharmacol 2014;171(8):2029-50. [PubMed: 24117165] 
68. Baines CP. The molecular composition of the mitochondrial permeability transition pore. Journal of molecular and cellular cardiology 2009;46(6):850-7. [PubMed: 19233198]

69. Niimi K, Yasui T, Hirose M, Hamamoto S, Itoh Y, Okada A, et al. Mitochondrial permeability transition pore opening induces the initial process of renal calcium crystallization. Free radical biology \& medicine 2012;52(7):1207-17. [PubMed: 22285391]

70. Santos JM, Tewari S, Lin JY, Kowluru RA. Interrelationship between activation of matrix metalloproteinases and mitochondrial dysfunction in the development of diabetic retinopathy. Biochemical and biophysical research communications 2013;438(4):760-4. [PubMed: 23891690]

71. Eirin A, Ebrahimi B, Zhang X, Zhu XY, Woollard JR, He Q, et al. Mitochondrial protection restores renal function in swine atherosclerotic renovascular disease. Cardiovasc Res 2014;103(4): 461-72. [PubMed: 24947415]

72. Eirin A, Williams BJ, Ebrahimi B, Zhang X, Crane JA, Lerman A, et al. Mitochondrial targeted peptides attenuate residual myocardial damage after reversal of experimental renovascular hypertension. J Hypertens 2014;32(1):154-65. [PubMed: 24048008]

73. Eirin A, Ebrahimi B, Kwon SH, Fiala JA, Williams BJ, Woollard JR, et al. Restoration of Mitochondrial Cardiolipin Attenuates Cardiac Damage in Swine Renovascular Hypertension. J Am Heart Assoc 2016;5(6).

** 74. Saad A, Herrmann SMS, Eirin A, Ferguson CM, Glockner JF, Bjarnason H, et al. Phase 2a Clinical Trial of Mitochondrial Protection (Elamipretide) During Stent Revascularization in Patients With Atherosclerotic Renal Artery Stenosis. Circ Cardiovasc Interv 2017;10(9). The first pilot study testing the efficacy of adjunctive mitoprotection in renovascular disease.

75. Chade AR, Rodriguez-Porcel M, Herrmann J, Krier JD, Zhu X, Lerman A, et al. Beneficial effects of antioxidant vitamins on the stenotic kidney. Hypertension 2003;42(4):605-12. [PubMed: 12925565]

76. Zhu XY, Chade AR, Rodriguez-Porcel M, Bentley MD, Ritman EL, Lerman A, et al. Cortical microvascular remodeling in the stenotic kidney: role of increased oxidative stress. Arterioscler Thromb Vasc Biol 2004;24(10):1854-9. [PubMed: 15308558]

77. Daghini E, Zhu XY, Versari D, Bentley MD, Napoli C, Lerman A, et al. Antioxidant vitamins induce angiogenesis in the normal pig kidney. Am J Physiol Renal Physiol 2007;293(1):F371-81. [PubMed: 17429028]

78. Kelsen S, Hall JE, Chade AR. Endothelin-A receptor blockade slows the progression of renal injury in experimental renovascular disease. Am J Physiol Renal Physiol 2011;301(1):F218-25. [PubMed: 21478482]

79. Chade AR, Tullos N, Stewart NJ, Surles B. Endothelin-a receptor antagonism after renal angioplasty enhances renal recovery in renovascular disease. J Am Soc Nephrol 2015;26(5):107180. [PubMed: 25377076]

80. Hackam DG, Duong-Hua ML, Mamdani M, Li P, Tobe SW, Spence JD, et al. Angiotensin inhibition in renovascular disease: a population-based cohort study. Am Heart J 2008;156(3):54955. [PubMed: 18760140]

81. Chrysochou C, Foley RN, Young JF, Khavandi K, Cheung CM, Kalra PA. Dispelling the myth: the use of renin-angiotensin blockade in atheromatous renovascular disease. Nephrol Dial Transplant 2012;27(4):1403-9. [PubMed: 21993376]

82. Evans KL, Tuttle KR, Folt DA, Dawson T, Haller ST, Brewster PS, et al. Use of renin-angiotensin inhibitors in people with renal artery stenosis. Clin J Am Soc Nephrol 2014;9(7):1199-206. [PubMed: 24903387]

83. Zhang X, Eirin A, Li ZL, Crane JA, Krier JD, Ebrahimi B, et al. Angiotensin receptor blockade has protective effects on the poststenotic porcine kidney. Kidney Int 2013;84(4):767-75. [PubMed: 23615504]

84. Cheung CM, Patel A, Shaheen N, Cain S, Eddington H, Hegarty J, et al. The effects of statins on the progression of atherosclerotic renovascular disease. Nephron Clin Pract 2007;107(2):c35-42. [PubMed: 17713349]

85. Chade AR, Zhu X, Mushin OP, Napoli C, Lerman A, Lerman LO. Simvastatin promotes angiogenesis and prevents microvascular remodeling in chronic renal ischemia. FASEB J 2006;20(10):1706-8. [PubMed: 16790524] 
86. Lavi R, Zhu XY, Chade AR, Lin J, Lerman A, Lerman LO. Simvastatin decreases endothelial progenitor cell apoptosis in the kidney of hypertensive hypercholesterolemic pigs. Arterioscler Thromb Vasc Biol 2010;30(5):976-83. [PubMed: 20203299]

87. Warner GM, Cheng J, Knudsen BE, Gray CE, Deibel A, Juskewitch JE, et al. Genetic deficiency of Smad3 protects the kidneys from atrophy and interstitial fibrosis in $2 \mathrm{~K} 1 \mathrm{C}$ hypertension. Am J Physiol Renal Physiol 2012;302(11):F1455-64. [PubMed: 22378822] 


\section{KEY POINTS}

- Atherosclerotic renovascular disease remains an important cause of renal failure in the elderly population.

- $\quad$ Compared with medical therapy, revascularization carries some substantial risk, without adding benefit with respect to renal function.

- The natural history of the disease involves transition from a hemodynamic component to a pro-inflammatory and pro-fibrotic disease.

- Renal inflammation, microvascular remodeling, and mitochondrial damage accelerate progression of renal injury and are important determinants of the response to revascularization.

- $\quad$ Therapies targeting these pathways have potential to preserve the structure and function of the stenotic kidney. 


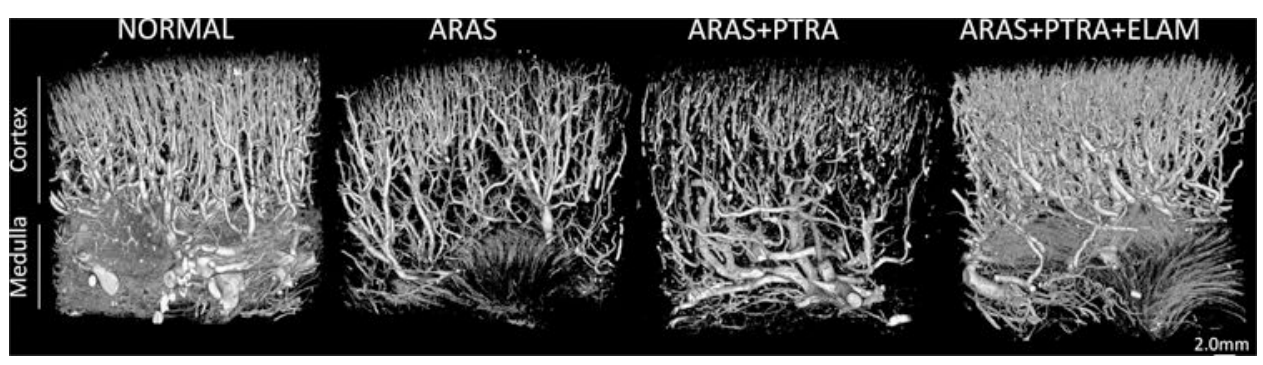

Figure 1.

Representative 3D micro-computer tomography images showing that treatment with percutaneous transluminal renal angioplasty (PTRA) and elamipretide (ELAM) increased the number of cortical and medullary microvessels in the swine stenotic-kidney. 